\title{
Sustained bromocriptine therapy in previously untreated patients with Parkinson's disease
}

\author{
AJ LEES, GM STERN \\ From the Department of Neurology, University College Hospital, London
}

SUMMARY The progress of 50 previously untreated patients with idiopathic Parkinson's disease taking maximum tolerated doses of bromocriptine is compared with patients who had taken levodopa. Twenty-eight of the bromocriptine treated patients showed sustained benefit for at least one year and in five this persisted longer than five years. Fewer of the late complications of levodopa therapy occurred in those taking bromocriptine; drug-induced dyskinesia was seen in only one patient and oscillations in performance were not observed. There was a tendency for deterioration to develop after two years treatment when patients then failed to respond well to levodopa. It was not possible to extend the period of effective control of disabilities by first giving bromocriptine.

It is now generally accepted that bromocriptine (2-bromo-alpha-ergocryptine), a dopaminergic agonist with presynaptic and postsynaptic effects, is an effective anti-Parkinsonian agent. ${ }^{1}$ Over short periods, benefit comparable to that seen with levodopa has been described, and partial replacement of levodopa has been reported to smooth out drug-induced oscillations ${ }^{2}$ and reduce levodopaprovoked dyskinesias. ${ }^{3}$ Yet in spite of over five years of clinical experience with bromocriptine there is still no general agreement as to its therapeutic role. This is in part due to the fact that most of the studies have been carried out in patients who had taken levodopa as well as other medications for several years and who were experiencing complications of chronic treatment. In an attempt to clarify the potential and longterm efficacy of bromocriptine and to determine whether the period of effective control of Parkinsonian disabilities could be extended, the sustained effects of maximum tolerated doses of bromocriptine in previously untreated patients has been studied and compared to a group of patients who had been given maximum tolerated doses of levodopa.

\section{Patients and methods}

In April of 1975 the first of 50 hitherto untreated, incapacitated patients with idiopathic Parkinson's

Address for reprint requests: Dr G Stern, University College Hospital, Gower Street, London, WC1E 6AU, UK.

Received 8 April 1981, and in revised form 21 July 1981 Accepted 8 August 1981 disease (23 male, 27 female) was admitted to the trial. Every other newly diagnosed patient was selected so that the cohort represents half of one hundred consecutively presenting Parkinsonians; the remainder entered a separate trial and are not considered further. The average age of onset of symptoms of the selected patients was 53 years $( \pm 15.0$ years) for men and 61 years $( \pm 10 \cdot 1$ years) for women and the mean duration of disease before bromocriptine treatment was two years (range 1-4 years). Most of the patients were mildly disabled. On the Hoehn and Yahr Scale ${ }^{4}$ eight were in Stage 1, 24 in Stage 2, 13 in Stage 3, four in Stage 4 and only one patient in Stage 5. Throughout the trial patients were assessed by the same clinicians using the Webster ${ }^{5}$ and North Western University Disability Rating Scales. ${ }^{6}$ The initial dose of bromocriptine was $2.5 \mathrm{mg}$ daily after the evening meal and this was increased by $2.5 \mathrm{mg}$ every three days up to $40 \mathrm{mg}$ daily, in three divided doses. Patients were advised to take the medication after meals and if nausea or vomiting emerged during the build-up period, metaclopramide was given thirty minutes before a meal. Above $40 \mathrm{mg}$ of bromocriptine daily, increases of $10 \mathrm{mg}$ were made twice weekly until a maximum tolerated dose was achieved. After a minimum period of two weeks on maximum dosage, and at varying intervals, a placebo indistinguishable from bromocriptine was given unbeknown to patient or assessor and continued for a fortnight. Patients who failed to detect the placebo switch were withdrawn from bromocriptine.

Significant benefit was defined as greater than $25 \%$ reduction in pre-treatment disabilities after one year of treatment. Successful responders were treated with bromocriptine for as long as they remained better than their pre-treatment level of disability. Those losing ground while on sustained bromocriptine medication were given, when tolerated, increasing amounts of 
bromocriptine before a further placebo switch determined whether bromocriptine should be withdrawn. Those patients who failed to improve initially and those who lost ground on sustained medication were then given maximum tolerated doses of levodopa in combination with a peripheral decarboxylase inhibitor (carbidopa). To simplify drug regimens in these patients, whenever possible bromocriptine was totally replaced by levodopa.

The overall results of the trial were then compared with those achieved in a group of idiopathic patients with mild disease treated between 1969-73 taking maximum tolerated doses of levodopa. These patients had been assessed using similar rating scales and scoring methods. The 35 patients ( 20 males and 15 females) selected had a mean age at onset of 54.6 years $( \pm 8.9) ; 53.2$ years for males $( \pm 9 \cdot 1)$ and $57 \cdot 0$ years $( \pm 7 \cdot 6)$ for females. The mean pre-treatment stage of severity on the Hoehn and Yahr Scale was $2 \cdot 2$ and no Stage 4 or 5 patients were included. The mean duration of disease before the onset of levodopa therapy was $2 \cdot 5$ years (range $0 \cdot 5-4$ years). The mean maximum dose of levodopa was $3 \cdot 8$ grams daily which, using the conventional conversion factor of division by four is equivalent to $950 \mathrm{mg}$ a day of levodopa in combination therapy; nine of these patients were also receiving anticholinergic medication and one amantadine.

\section{Results}

BROMOCRIPTINE RESPONDERS

After one year's treatment $28(56 \%)$ patients had gained benefit greater than $25 \%$ improvement in overall disability scores which varied from modest to marked on a mean daily dose of $70 \mathrm{mg}$ bromocriptine (range 10-160 mg). Bradykinesia and rigidity tended to improve first, but tremor also responded. Three patients deteriorated at doses below $10 \mathrm{mg}$ a day of bromocriptine before improving on higher doses, but in general improvement was first evident at about $30 \mathrm{mg}$ a day. Increases above $100 \mathrm{mg}$ daily rarely produced additional benefit.

By December 1980, 17 of the 28 patients were still taking bromocriptine with benefit (table 1), five of whom had maintained improvement for longer than five years. In most patients gradual emergence of former disabilities began to appear after one or two years of medication. Thus at two years 10 of 15

Table 1 Duration of bromocriptine treatment and therapeutic response of patients December 1980 (17/28)

\begin{tabular}{llll}
\hline Duration (yr) & No of patients & $\begin{array}{c}\text { No > 25\% } \\
\text { improvement }\end{array}$ & $\begin{array}{c}\text { No who maintaincd } \\
\text { initial response }\end{array}$ \\
\hline 1 & 6 & 6 & 5 \\
2 & 2 & 2 & 2 \\
3 & 3 & 2 & 1 \\
4 & 1 & 0 & 0 \\
5 & 5 & 4 & 2 \\
\hline
\end{tabular}

patients had maintained their initial response but after three years only four of 11 patients still showed comparable improvement. In patients losing ground on sustained bromocriptine therapy attempted increases in bromocriptine dosage were always unsuccessful either because of intolerable side-effects or lack of further therapeutic response. There were 11 patients who had taken medication with benefit for a mean period of 3.3 years (range $1-5$ years) before treatment was withdrawn; in eight this was because of increasing incapacity and in three because of the late emergence of unacceptable side-effects (toxic confusional states 2; ergotism 1). To these patients the addition or complete substitution of levodopa with carbidopa failed to lead to further improvement; one died in a severely akinetic state from a chest infection.

\section{BROMOCRIPTINE FAILURES}

Twenty-two patients $(44 \%)$ failed to gain benefit as defined above during the first year of bromocriptine treatment. Unacceptable dose-limiting adverse reactions at sub-therapeutic doses were largely responsible and included giddiness (four patients), nausea (two patients), vomiting (two patients), toxic confusional states (two patients), visual pseudohallucinations (two patients), malaise and sedation (two patients) and postural hypotension with syncope (one patient). Modest benefit occurred in many of these patients but the severity of the side-effects made continuation of therapy impractical. Four patients who were able to tolerate up to $120 \mathrm{mg}$ daily of bromocriptine failed to show definite benefit but this group of early failures as a whole could only tolerate a mean daily dose of $40 \mathrm{mg}$ of bromocriptine. Fourteen of these patients subsequently responded well to levodopa; side-effects on levodopa were mild (nausea three patients, mild intermittent confusion one patient) and two of the patients who had failed to benefit from $120 \mathrm{mg}$ of bromocriptine benefited from doses of combination therapy of $750 \mathrm{mg}$ and $1000 \mathrm{mg}$ respectively. Most of these patients are still better after up to five years of levodopa treatment although peak-dose dyskinesias and end-of-dose deterioration have developed in seven.

The eight patients who failed to respond to bromocriptine or levodopa included two refractory to high doses of both drugs. It is possible that these patients may have been suffering from a bradykineticrigid form of multi-system degeneration and one has now died after an illness lasting only four years. The remaining six patients developed similar adverse reactions on both medications with isolated hallucinations or toxic confusional states (four patients) nausea and vomiting (two patients). 
Table 2 Side-effects of bromocriptine (dose-limiting adverse reactions in parenthesis)

\begin{tabular}{ll}
\hline & No of cases \\
\hline Nausea & $19(2)$ \\
Dizziness & $11(4)$ \\
Sedation & $6(1)$ \\
Vomiting & $5(2)$ \\
Visual pseudohallucinations & $5(4)$ \\
Toxic confusional states & $5(5)$ \\
Muzzy-headedness & $5(1)$ \\
Malaise & $3(1)$ \\
Heartburn & $3(0)$ \\
Nasal congestion & $3(0)$ \\
Digital vasospasm & $3(0)$ \\
Postural hypotension & $2(1)$ \\
Metallic taste in mouth & $2(0)$ \\
Unpleasant body odour & $2(0)$ \\
Anorexia & $2(0)$ \\
Weight gain & $2(0)$ \\
Abnormal movements & $1(1)$ \\
Erythromelalgia & $1(1)$ \\
Ergotism & $1(1)$ \\
Hiccoughs & $1(0)$ \\
Urinary symptoms & $1(0)$ \\
Haematemesis & $1(1)$ \\
Aching of shins & $1(0)$ \\
\hline
\end{tabular}

ADVERSE SIDE-EFFECTS

These and the dose-limiting side-effects are shown in table 2. Adverse reactions were common early in the course of treatment when giddiness, malaise and psychiatric complications were particularly troublesome. Although nausea, anorexia and occasionally vomiting were commonly reported these could usually be countered by taking bromocriptine after meals. In six patients metaclopramide was required for an average period of six weeks during the buildup phase. During chronic administration of bromocriptine it was possible to discontinue metaclopramide within six months without re-emergence of gastrointestinal adverse effects. Mild dose dependent elevation of liver enzymes occurred in two patients.

Of the 50 patients, peak dose dyskinesias occurred in only one patient (Stage 4 disability) who developed oro-facial movements after two months of $40 \mathrm{mg}$ bromocriptine daily. End-of-dose deterioration, the on-off phenomenon and end-of-dose dystonia have not been encountered although toxic confusional states and visual pseudo-hallucinations occurred. No electrocardiographic abnormalities were seen during treatment and chest radiographs on 20 patients after treatment for periods ranging from three months to five years showed no evidence of pleural or pulmonary disease.

HIGH DOSE LEVODOPA RESULTS

Twenty-nine comparable patients derived worthwhile improvement and in 14 the response was marked (more than a $50 \%$ reduction in disabilities); and a mean overall $50 \%$ initial improvement in functional capacities occurred. Six patients were
Table 3 A comparison of bromocriptine therapy with high dose L-dopa treatment

\begin{tabular}{lll}
\hline & $\begin{array}{l}\text { Bromocriptine } \\
\text { mean dose } 70 \mathrm{mg} / \text { day }\end{array}$ & $\begin{array}{l}\text { Levodopa mean dose } \\
3800 \mathrm{mg} / \text { day }\end{array}$ \\
\hline $\begin{array}{l}\text { Initial improvement } \\
\text { of }>25 \% \text { at 1 year }\end{array}$ & $56 \%(28 / 50)$ & $74 \%(21 / 29)$ \\
$\begin{array}{c}\text { Peak-dose dyskinesias } \\
\text { after 1 year }\end{array}$ & $4 \%(1 / 28)$ & $65 \%(19 / 29)$ \\
$\begin{array}{c}\text { End-of-dose } \\
\text { deterioration after } \\
3 \text { years }\end{array}$ & $0(0 / 11)$ & $37 \%(10 / 27)$ \\
\hline
\end{tabular}

unable to tolerate the medication, three because of gastrointestinal side-effects, two because of toxic confusional states and one because of postural hypotension. Deterioration occurred with sustained therapy and only 13 maintained their initial response at three years. After three years the mean overall functional improvement had fallen to $41 \%$ and three patients had died.

The results and complications seen during longterm therapy are compared with those occurring with bromocriptine in table 3 .

\section{Discussion}

This study shows that maximum tolerated doses of bromocriptine can produce improvement in Parkinsonian disabilities comparable to that seen with levodopa; that the response is probably independent of disease severity and that benefit may be sustained for several years. For instance, 13 of 15 patients gained at least a $50 \%$ improvement in overall disability scores which persisted for over a year; rigidity, bradykinesia and tremor were equally benefited.

Retrospective comparison with our levodopa treated patients matched for age, duration of disease and disease severity indicates that fewer bromocriptine treated patients improved as defined by a greater than $25 \%$ reduction in disability scores $(56 \%$ of patients compared with $74 \%$ ). Furthermore, a number of patients who were unable to tolerate levodopa alone in our original study might have done well with a peripheral decarboxylase inhibitor. It should be pointed out however that the two groups of patients are not exactly comparable; for example some of the levodopa treated group were already on anticholinergic medication. The poorer overall response to bromocriptine was largely due to a higher incidence of central side-effects.

Only limited conclusions may be drawn concerning the comparability of levodopa and bromocriptine in responding Parkinsonians. Reported drug response curves to both drugs have indicated that 2.0 grams of levodopa is slightly more potent 
than $100 \mathrm{mg}$ of bromocriptine. ${ }^{2}$ In the present study we did not perform appropriate substitution changes, but our general clinical impression would accord approximately with this equivalence. It remains possible that larger doses of bromocriptine might have been tolerated with greater benefit if the peripheral dopaminergic agonist domperidone had been concurrently prescribed $^{8}$ although in our patients, increments above $100 \mathrm{mg}$ of bromocriptine daily rarely afforded further benefit.

The pattern of deterioration or diminished responsiveness to bromocriptine medication is very similar to that recorded in our own three year review of levodopa therapy.$^{9}$ Some of the dopaminergic agonist effects of bromocriptine probably depend upon pre-synaptic actions and progressive degeneration of nigro-striatal dopaminergic neurons would seem to be the most likely explanation for the waning response of the two drugs.

Of the 28 patients who took bromocriptine for over a year only one developed peak-dose chorea $(3.5 \%)$ compared to $65 \%$ of our age and severity matched patients on maximum tolerated doses of levodopa. This suggests that levodopa is at least partially responsible for lowering the threshold to druginduced dyskinesias. None of the 11 patients who have taken bromocriptine for more than three years have developed end-of-dose deterioration compared with $35 \%$ of our patients on levodopa. This difference may be attributed to a progressive inability of dopaminergic systems to convert dopa to dopamine and represent a potential advantage for bromocriptine.

Giving maximum tolerated doses of bromocriptine to untreated, disabled patients with Parkinson's disease can give rise to improvement comparable to levodopa. However, fewer patients can tolerate a therapeutic dose and deterioration after two years with a subsequent poor response to levodopa makes it unlikely that the total duration of effective therapy for Parkinson's disease can be extended by first giving bromocriptine.

We are grateful to Sandoz UK for generous and sustained supplies of bromocriptine.

\section{References}

${ }^{1}$ Stern GM, Lees AJ. Bromocriptine in Parkinson's Disease. Brit J Hosp Med 1978;666-70.

- Parkes JD, Debono AG, Marsden CD. Bromocriptine in Parkinsonism; Longterm Treatment, Dose Response and Comparison with L-dopa. $J$ Neurol Neursurg Psychiatry 1976;39:1101-8.

${ }^{3}$ Calne DB, Plotkin C, Williams AC, Nutt JG. Neophytides, A, Teychenne, PF. Longterm Treatment of Parkinsonism with Bromocriptine. Lancet 1978;1: 735-8.

${ }^{4}$ Hoehn MM, Yahr MD. Parkinsonism, Onset, Progression and Mortality. Neurology (Minneap) 1967; 17:427-42.

${ }^{5}$ Webster DD. Critical Analysis of the Disability in Parkinson's Disease. Mod Treatment 1968;5:257-82.

${ }^{6}$ Canter GJ, De La Torre R, Mier MA. A Method for Evaluating Disability in Patients with Parkinson's Disease. J Nerv Ment Dis 1961;133:143-7.

${ }^{7}$ Lees AJ, Haddad S, Shaw KM, Kohout LJ, Stern GM. Bromocriptine in Parkinsonism-a Longterm Study. Arch Neurol 1978;35:503-5.

${ }^{8}$ Quinn N, Illas A, L'Hermitte F, Agid Y. Bromocriptine and Domperidone in the Treatment of Parkinson's Disease. Neurology (Minneap) 1981 ;31:662-8.

${ }^{9}$ Hunter KR, Shaw KM, Laurence DR, Stern GM. Sustained Levodopa Therapy in Parkinsonism. Lancet $1973 ; 2: 928-31$. 